Jurnal Interpretasi Hukum | ISSN: 2746-5047

Vol. 2, No. 3-Desember 2021, Hal. 525-530| Tersedia online di

https://www.ejournal.warmadewa.ac.id/index.php/juinhum

DOI: https://doi.org/10.22225/juinhum.2.3.4131.525-530

\title{
PERLINDUNGAN HUKUM BAGI PEMILIK KARTU ELEKTRONIK DALAM TRANSAKSI E-COMMERCE
}

\author{
Putu Widhiatmika Coryka, I Nyoman Putu Budiartha, Made Puspasutari Ujianti \\ Fakultas Hukum, Universitas Warmadewa, Denpasar-Bali, Indonesia \\ widhiatmikacoryka@gmail.com, budiarthaputu59@gmail.com, puspasutariujianti@gmail.com
}

\begin{abstract}
Abstrak
Kontrak elektronik salah satu bentuk kontrak baru yang mendapatkan perlindungan secara khusus dalam Undang-Undang Nomor 11 Tahun 2008 tentang Informasi dan Transaksi Elektronik. Secara umum kontrak elektronik berbeda sekali dengan bentuk kontrak biasa (konvensional), oleh karenanya akan sangat sulit untuk diterapkan secara langsung syarat-syarat terjadinya kontrak konvensional pada kontrak elektronik (online contract) ini. Tujuan penelitian ini untuk mengungkap keabsahan kontrak elektronik pada perjanjian kartu kredit serta perlindungan hukum bagi pemilik kartu kredit dalam transaksi e-commerce. Penelitian ini dilakukan dengan menggunakan penelitian hukum Normatif dengan mengaplikasikan pendekatan perundang-undangan. Teknik pengumpulan bahan hukum dilakukan dengan teknik menginventarisasi peraturan perundang-undangan serta pencatatan. Penelitian ini menggunakan bahan hukum primer dan sekunder yang kemudian diolah menggunakan logika deduktif dengan analisis interpretasi hukum dan argumentasi hukum disajikan secara deskriptif. Hasil penelitian mengungkapkan bahwa dalam Undang-undang Nomor 8 Tahun 1999 terdapat peraturan yang melindungi para pihak yang melakukan transaksi E-Commerce. Kontrak elektronik pada dasarnya sama seperti kontak tertulis dan memiliki kekuatan hukum dan akibat hukum yang sah selama memenuhi persyaratan undang-undang. Perlindungan hukum yang diberikan Pasal 26 Undang-undang Nomor 8 Tahun 1999 memberikan perlindungan bagi konsumen dengan mewajibkan pelaku usaha yang memperdagangkan jasa, untuk memenuhi jaminan dan/atau garansiyang disepakati atau/yang diperjanjikan.
\end{abstract}

Kata Kunci: Kartu Kredit, Kontrak Elektronik, Perlindungan Hukum

\begin{abstract}
Electronic contracts are one of the new forms of contracts that get special protection in Law Number 11 of 2008 concerning Information and Electronic Transactions. In general, electronic contracts are very different from ordinary (conventional) forms of contract, therefore it will be very difficult to directly apply the conditions for the occurrence of conventional contracts to this electronic contract (online contract). The purposes of this study are to reveal the validity of electronic contracts in credit card agreements and legal protection for credit card owners in e-commerce transactions. This research was conducted using normative legal research by applying a statutory approach. The technique of collecting legal materials is carried out by taking inventory of laws and regulations and recording techniques. This study uses primary and secondary legal materials which are then processed using deductive logic with analysis of legal interpretation and legal arguments presented descriptively. The results of the study reveal that in Law Number 8 of 1999 there are regulations that protect the parties who carry out E-Commerce transactions. Electronic contracts are basically the same as written contacts and have legal force and legal consequences as long as they meet statutory requirements. The legal protection provided by Article 26 of Law Number 8 of 1999 provides protection for consumers by requiring business actors who trade services to fulfill the agreed or/or agreed guarantees and/or guarantees.
\end{abstract}

Keywords: Credit Card, Electronic Contract, Legal Protection

\section{PENDAHULUAN}

Perkembangan teknologi telah memasuki ke berbagai bidang kehidupan manusia, seperti bidang pendidikan, perdagangan, kesehatan, perbankan, asuransi, hiburan dan berbagai bidang lainnya. Salah satu bentuk perkembangan teknologi adalah komputer. Komputer kini tidak lagi dapat dipisahkan dari semua aktivitas masyarakat, salah satunya nampak dalam bidang perbankan. Saat ini, bidang perbankan tidak mungkin dapat beroperasi tanpa komputer, komputer bukan lagi merupakan faktor pendukung bagi semua aktifitas perbankan tetapi sudah merupakan faktor utama dalam aktivitas itu sendiri, karena tanpa komputer segala aktifitas perbankan tidak dapat berjalan. Teknologi informasi yang sangat pesat menimbulkan adanya suatu gaya baru dalam sistem perdagangan. Beberapa tahun 
terakhir perdagangan melalui media internet semakin marak terjadi di Indonesia. Bahkan jual beli di media internet menggunakan facebook atau handphone sebagai alat pemasarannya. Dengan perdagangan lewat internet ini berkembang pula sistem bisnis virtual, seperti virtual store dan virtual company di mana pelaku bisnis menjalankan bisnis dan perdagangannya melalui media internet dan tidak lagi mengandalkan bisnis perusahaan konvensional yang nyata.

Perdagangan kini tidak dilakukan secara konvensional yaitu secara lisan atau tertulis, tetapi juga dapat dilaksanakan secara elektronik, yaitu dengan Menggunakan komputer melalui media internet. Internet sendiri merupakan salah satu bentuk perkembangan teknologi informasi yang memungkinkan semua kegiatan dilakukan dengan menggunakan komputer. Ide awal lahirnya internet berasal dari seorang ilmuwan bernama J.C.R. Licklider yang memimpikan adanya sebuah jaringan global yang saling terkoneksi dengan menggunakan komputer sehingga memungkinkan setiap orang dengan mudah dapat mengakses data dan program dari sebuah site (Ustadiyanto, 2002). Dengan adanya fenomena yang demikian ini, yakni semakin majunya ilmu pengetahuan dan teknologi yang merupakan motor penggerak bagi produktivitas dan efisiensi produsen atas barang atau jasa yang dihasilkannya dalam rangka mencapai sasaran usaha, maka perlindungan hukum terhadap konsumen dipandang sangat penting keberadaanya. Sebab dalam rangka mengejar produktivitas dan efisiensi tersebut, pada akhirnya baik secara langsung atau tidak langsung, konsumen lah yang menanggung dampaknya (Hartono, 1992). Internet sebagai suatu perkembangan teknologi informasi telah menyebabkan dunia menjadi tanpa batas dan menyebabkan perubahan sosial yang secara signifikan berlangsung demikian cepat. Internet telah membuat dunia menjadi terasa tanpa batas bagi para pelaku usaha dalam bidang perdagangan, melalui internet pelaku usaha dapat melakukan transaksi apapun dengan siapapun tanpa terbatas oleh batas geografis Negara. Setiap kegiatan dalam bidang perdagangan, seperti penawaran (promosi), pemesanan barang, permintaan barang dan sebagainya dapat dilakukan melalui internet.

Para pelaku bisnis, yaitu penjual dan pembeli, dapat melakukan transaksiperdagangan apapun tanpa perlu untuk bertemu secara face to face atau bertemu langsung, karena dengan melalui internet transaksi perdagangan dapat dilakukan hanya dengan menggunakan E-Mail. Hal ini tentu saja sangat menguntungkan karena akan sangat menghemat waktu para pelaku bisnis yang biasanya sangat sibuk.Transaksi perdagangan yang dilakukan secara elektronik dengan menggunakan media internet seringkali disebut sebagai Electronic Commerce (E-Commerce). Dengan masuknya media internet dalam dunia perdagangan/bisnis, banyak hal-hal mengalami perubahan, seperti kedekatan para pihak dalam bertransaksi menjadi semakin renggang, karena masing-masing pihak praktis tidak mengenal secara dekat satu sama lain (pengenalan hanya diketahui melalui media komputer), ketidakjelasan mengenai barang yang ditawarkan, terlebih apabila barang yang ditawarkan membutuhkan penanganan secara fisik (seperti parfum dan obat-obatan), kepastian bahwa barang yang dikirim sesuai dengan barang dipesan, padahal kita ketahui bahwa hubungan yang timbul antara konsumen dengan pelaku usaha senantiasa dimaksudkan agar kedua belah pihak menikmati keuntungan. Kondisi inilah yang seringkali timbul dalam setiap transaksi dengan mempergunakan internet. Sebaliknya Undang-undang Perlindungan Konsumen yang sekarang berlaku di Indonesia masih berbasis pada sesuatu yang sifatnya fisik belum kepada virtual/maya. Transaksi perdagangan melalui media elektronik atau lazim disebut Electronic Commerce menyisakan berbagai permasalahan yang belum ada pengaturannya. Electronic Commerce terbentuk dari berbagai sub sistem yang tersusun secara sistematis, dan masing-masing sub sistem tersebut memiliki permasalahanya masing-masing. Namun disisi lain, hal ini juga mempunyai kekurangan yaitu metode transaksi elektronik yang tidak mempertemukan pelaku usaha dan konsumen secara langsung serta tidak dapatnya konsumen melihat secara langsung barang yang dipesan berpotensi menimbulkan permasalahan yang merugikan konsumen (Wulandari, 2018).

Penelitian terdahulu yang relevan dengan penelitian ini mengungkapkan bahwa bentuk perlindungan hukum bagi konsumen dalam UUITE yaitu Pasal 2 UUITE Undang-undang ini berlaku untuk setiap orang yang melakukan perbuatan hukum, baik yang berada di wilayah hukum Indonesia maupun di luar wilayah hukum Indonesia yang memiliki akibat hukum di Indonesia atau di luar wilayah hukum Indonesia yang merugikan kepentingan Indonesia; e) Dalam pasal ini pelaku usaha yang menawarkan produk melalui system elektronik harus menyediakan informasi yang lengkap dan benar berkaitan dengan syarat kontrak, produsen dan produk yang ditawarkan (Rusmawati, 2013). Sedangkan menurut Pradnyaswari, Ida Ayu Eka Westra (2020) berpendapat bahwa di Indonesia 
terdapat dua upaya hukum yang konsumen dapat tempuh jika mendapat kerugian dalam transaksi perdagangan online yaitu dengan jalur pengadilan atau luar pengadilan (konsultasi, negoisasi, mediasi, atau penilaian para ahli) sesuai kesepakatan masing-masing pihak. Lebih lanjut, menurut Sari (2019) memaparkan bahwa bentuk perlindungan hukum terhadap konsumen dalam transaksi ecommerce telah disesuaikan dengan undang-undang perlindungan konsumen Nomor 8 Tahun 1999 (Tentang Perlindungan Konsumen) Serta Undang-undang Nomor 11 Tahun 2008 tentang Informasi dan Transaksi Elektronik. Dari fenomena tersebut maka ingin dilakukan penelitian yang bertujuan untuk mengungkap keabsahan kontrak elektronik pada perjanjian kartu kredit serta perlindungan hukum bagi pemilik kartu kredit dalam transaksi e-commerce.

\section{METODE PENELITIAN}

Metode yang digunakan dalam penelitian ini adalah penelitian hukum normatif, dengan menggunakan pendekatan perundang-undangan melalui pengkajian terhadap produk perundang-undangan yang mengatur secara khusus tentang Perlindungan Hukum Bagi Pemilik Kartu Elektronik dalam Transaksi E-Commerce. Adapun pengumpulan bahan hukum yang digunakan dalam penelitian ini teknik menginventarisasi Peraturan Perundang-undangan, pencatatan dan dikaitkan dengan jenis Penelitian Normatif maupun literatur-literatur yang ada kaitannya dengan pokok pembahasan. Penelitian ini menggunakan bahan hukum primer dan sekunder. Sumber bahan hukum primer yaitu bahan-bahan hukum yang mengikat dan terdiri dari Undang-undang Dasar Negara Kesatuan Republik Indonesia tahun 1945 Undang-undang Nomor 11 tahun 2008 tentang Informasi Transaksi Elektronik, Undangundang Nomor 8 tahun 1999 tentang Perlindungan Konsumen, Kitab Undang-undang Hukum Perdata (KUHPer). Sumber bahan hukum sekunder yaitu bahan hukum sekunder bersumber dari buku Perpustakaan. Analisa bahan hukum Bahan hukum yang telah dikumpulkan selanjutnya diolah menggunakan logika deduktif dengan analisis interpretasi hukum dan argumentasi hukum disajikan secara deskriptif (Harahap, 2014).

\section{HASIL DAN PEMBAHASAN}

\section{Keabsahan Kontrak Elektronik pada Perjanjian Kartu Kredit}

Kontrak elektronik merupakan salah satu bentuk kontrak baru yang mendapatkan perlindungan secara khusus dalam Undang-Undang Nomor 11 Tahun 2008 tentang Informasi dan Transaksi Elektronik (yang selanjutnya disebut UU ITE), khususnya melalui Pasal 1 angka 17, kontrak elektronik adalah perjanjian para pihak yang dibuat melalui sistem elektronik. Sedangkan sistem elektronik itu sendiri adalah serangkaian perangkat dan prosedur elektronik yang berfungsi mempersiapkan, mengumpulkan, mengolah, menganalisis, menyimpan, menampilkan, mengumumkan, mengirimkan, dan atau menyebarkan informasi elektronik. Hal ini diatur dalam Pasal 1 angka 5 UU ITE. Sebelum diberlakukannya UU ITE, masyarakat yang telah memanfaatkan jenis kontrak elektronik, berpedoman pada Kitab Undang-undang Hukum Perdata (yang selanjutnya disebut KUHPdt) Pasal 1320 sebagai perlindungan hukumnya. Sebelum diberlakukannya UU ITE, masyarakat yang telah memanfaatkan jenis kontrak elektronik, berpedoman pada Kitab Undang- undang Hukum Perdata (yang selanjutnya disebut KUHPdt) sebagai perlindungan hukumnya. Pada hakekatnya kontrak elektronik adalah perjanjian yang disepakati para pihak yang membuatnya, hanya medium atau sarana yang membedakannya dengan kontrak konvensional, karena kontrak elektronik menggunakan sistem elektronik. Melalui sistem tersebut para pihak tidak bertemu atau bertatap muka secara langsung. Mereka hanya perlu mengisikan kontrak yang telah tersedia, dan dikirimkan melalui internet. Dalam suatu perjanjian/kontrak selalu melibatkan para pihak yang melakukan penawaran, dan selanjutnya biasanya diikuti dengan penerimaan. Offer atau penawaran adalah suatu infatuation to enter in to a binding to agreement (Badrulzaman, 2000). Suatu tawaran adalah benar merupakan suatu tawaran jika pihak-pihak lain memandangnya sebagai suatu tawaran. perlindungan konsumen adalah bagian dari hukum konsumen yang memuat asas-asas atau kaidah-kaidah yang bersifat mengatur dan mengandung sifat yang melindungi kepentingan konsumen, sedangkan hukum konsumen adalah hukum yang mengatur hubungan dan masalah antara berbagai pihak satu sama lain berkaitan dengan barang atau jasa konsumen di dalam pergaulan hidup (Nasution, 2001).

Pada hakekatnya kontrak elektronik adalah perjanjian yang disepakati para pihak yang membuatnya, hanya medium atau sarana yang membedakannya dengan kontrak konvensional, karena kontrak elektronik menggunakan sistem elektronik. Melalui sistem tersebut para pihak tidak bertemu 
atau bertatap muka secara langsung. Mereka hanya perlu mengisikan kontrak yang telah tersedia, dan dikirimkan melalui internet. Beberapa cara pengiriman dokumen elektronik berupa kontrak elektronik adalah dengan cara

1. Posting pada WEB.

2. Mengirim melalui internet menggunakan FTP atau e-mail.

3. FTP (Internet File Transfer Protocol).

4. GEDI (Generic Electronic Document Interchange).

5. Adobe Acrobate.

6. Adobe Reader.

7. MIME (Multipurpose Internet Mail Extensions).

8. Kontrak melalui chatting dan video conference.

Secara umum kontrak elektronik berbeda sekali dengan bentuk kontrak biasa (konvensional), oleh karenanya akan sangat sulit untuk diterapkan secara langsung syarat- syarat terjadinya kontrak konvensional pada kontrak elektronik (online contract) ini.

\section{Perlindungan Hukum Bagi Pemilik Kartu Kredit Dalam Transaksi E-Commerce}

Undang-undang Perlindungan Konsumen menyatakan bahwa, perlindungan konsumen adalah segala upaya yang menjamin adanya kepastian hukum untuk memberi perlindungan kepada konsumen. Cakupan perlindungan konsumen itu dapat dibedakan dalam dua aspek, yaitu

1. Perlindungan terhadap kemungkinan barang yang diserahkan kepada konsumen tidak sesuai dengan apa yang telah disepakati.

2. Perlindungan terhadap diberlakukannya syarat-syarat yang tidak adil kepada konsumen.

Hukum perlindungan konsumen yang berlaku di Indonesia memiliki dasar hukum yang telah ditetapkan oleh pemerintah. Dengan adanya dasar hukum yang pasti, perlindungan terhadap hak-hak konsumen bisa dilakukan dengan penuh optimisme. Pengaturan tentang hukum perlindungan konsumen telah diatur dalam Undang-undang No. 8 Tahun 1999 tentang Perlindungan Konsumen. Pasal 1 angka 1 UUPK disebutkan bahwa Perlindungan konsumen adalah segala upaya yang menjamin adanya kepastian hukum untuk memberi perlindungan kepada konsumen. Kepastian hukum untuk memberi perlindungan kepada konsumen berupa perlindungan terhadap hak-hak konsumen, yang diperkuat melalui undang-undang khusus, memberi harapan agar pelaku usaha tidak bertindak sewenang-wenang yang selalu merugikan hak-hak konsumen.

Keinginan yang hendak dicapai dalam perlindungan konsumen adalah menciptakan rasa aman bagi konsumen dalam memenuhi kebutuhan hidup. Segala upaya yang dimaksudkan dalam perlindungan konsumen tersebut tidak saja terhadap tindakan preventif tetapi juga tindakan represif dalam semua bidang perlindungan yang diberikan kepada konsumen, maka pengaturan perlindungan konsumen dilakukan dengan (Barkatulah, 2008).

1. Menciptakan sistem perlindungan konsumen yang mengandung unsur keterbukaan akses informasi, serta menjamin kepastian hukum.

2. Melindungi kepentingan konsumen pada khususnya dan kepentingan seluruh pelaku usaha.

3. Meningkatkan kualitas barang dan pelayanan jasa.

4. Memberikan perlindungan kepada konsumen dari praktek usaha yang menipu dan menyesatkan.

5. Memadukan penyelenggaraan, pengembangan, dan pengaturan perlindungan konsumen dengan bidang-bidang perlindungan pada bidang-bidang lainnya

Tujuan perlindungan konsumen yaitu

1. Meningkatkan kesadaran, kemampuan dan kemandirian konsumen untuk melindungi diri.

2. Mengangkat harkat dan martabat konsumen dengan cara menghindarkannya dari ekses negatif pemakaian barang dan/atau jasa.

3. Meningkatkan pemberdayaan konsumen dalam memilih, menentukan dan menuntut hakhaknya sebagai konsumen.

4. Menciptakan sistem perlindungan konsumen yang mengandung unsur kepastian hukum dan keterbukaan informasi serta akses untuk mendapatkan informasi.

5. Menumbuhkan kesadaran pelaku usaha mengenai pentingnya perlindungan konsumen sehingga tumbuh sikap yang jujur dan bertanggung jawab dalam berusaha. 
6. Meningkatkan kualitas barang dan/atau jasa yang menjamin kelangsungan usaha produksi barang dan/atau jasa, kesehatan, kenyamanan, keamanan, dan keselamatan konsumen (Saliman, 2015).

Untuk menentukan apakah transaksi E-Commerce tersebut adalah sah maka harus terlebih dahulu dilihat apakah transaksi E-Commerce tersebut telah memenuhi syarat sahnya perjanjian. Syarat pertama dipenuhi apabila para pihak dalam transaksi E-Commerce yaitu customer (pembeli), dan merchant (penjual) terlebih dahulu mencapai kata sepakat untuk melakukan transaksi tersebut. Kesepakatan tersebut harus terjadi tanpa adanya paksaan, kekhilafan atau penipuan. Apabila ketentuan ini telah dipenuhi, maka syarat pertama telah terpenuhi. Syarat kedua adalah kedua belah pihak harus cakap untuk melakukan transaksi E-Commerce tersebut. Cakap disini artinya adalah sudah dewasa dan tidak berada dibawah pengampuan. Perlindungan Konsumen memberikan perlindungan bagi konsumen dengan mewajibkan pelaku usaha yang memperdagangkan jasa, untuk memenuhi jaminan dan/atau garansi yang disepakati atau/yang diperjanjikan. Customer diharapkan mendapatkan Perlindungan dengan menyediakan sistem keamanan dari pihak bank dan menjamin kerahasiaan data kartu kreditnya.

\section{SIMPULAN DAN SARAN}

\section{Simpulan}

Kontrak elektronik pada dasarnya sama seperti kontrak tertulis dan memiliki kekuatan hukum dan akibat hukum yang sah seperti yang termaktub dalam Pasal 11 dan Pasal 12 Rancangan Undangundang Informasi dan Transaksi Elektronik menjelaskan bahwa tanda tangan elektronik (Digital Signature) memiliki kekuatan hukum dan akibat hukum yang sah dan teknik, metode, sarana, atau proses pembuatan tanda tangan elektronik (Digital Signature) memiliki hukum yang sah selama memenuhi persyaratan undang-undang. Perlindungan hukum yang diberikan Pasal 26 Undang-undang Nomor 8 Tahun 1999 memberikan perlindungan bagi konsumen dengan mewajibkan pelaku usaha yang memperdagangkan jasa, untuk memenuhi jaminan dan/atau garansi yang disepakati atau/yang diperjanjikan. menjamin kerahasiaan data kartu kreditnya. Perlindungan hukum bagi pemilik kartu kredit dalam transaksi E-Commerce dengan melarang kepada seorang (merchant) menggunakan dan atau mengakses komputer dan atau sistem elektronik secara tanpa hak atau melampaui wewenangnya dengan maksud keuntungan atau memperoleh informasi keuangan dari lembaga perbankan atau lembaga keuangan, penerbit kartu kredit, atau kartu pembayaran atau yang mengandung data laporan nasabahnya. Merchant dilarang menggunakan dan atau mengakses dengan cara apapun kartu kredit atau kartu pembayaran milik orang lain secara tanpa hak dalam transaksi elektronik untuk memperoleh keuntungan.

\section{Saran}

Kepada Pemerintah untuk memberikan perlindungan kepada para pihak terkait yang melakukan transaksi melalui media elektronik (E-Commerce) dengan menegakan peraturan hukum yang berlaku untuk mengatur transaksi E-Commerce agar memberikan rasa aman kepada para pelaku perdagangan baik penjual dan pembeli dan Kepada pengusaha (Merchant) harus lebih berperan aktif untuk memintakan informasi identitas pengguna kartu kredit dan menyimpan rahasia penggunaan nomor PIN (Personal Identification Number) pembeli (Customer). Kepada para pemilik kartu kredit harus lebih berhati-hati dalam melakukan transaksi E-Commerce dengan mengganti nomor PIN (Personal Identification Number) setiap setelah melakukan transaksi E-Commerce agar tidak dapat digunakan oleh pihak-pihak yang tidak bertanggung jawab. Dan kepada pihak penerbit Kartu Kredit atau Bank agar setiap pengguna Kartu Kredit yang melakukan transaksi dimintai informasi atas kebenaran kepada pemilik kartu setiap pemilik kartu melakukan transaksi.

\section{DAFTAR PUSTAKA}

Badrulzaman, M. D. (2000). E-Commerce Tinjauan dari Aspek Keperdataan. Seminar Tentang ECommerce Dan Mekanisme Penyelesaian Masalahnya Melalui Arbitrase/Alternatif Penyelesaian Sengketa.

Barkatulah, A. H. (2008). Hukum Perlindungan Konsumen (Kajian Teoritis dan Perkembangan Pemikiran. Nusa Media, Bandung.

Harahap, M. Y. (2014). Hukum Acara Perdata. Sinar Grafika, Jakarta. 
Hartono, S. R. (1992). Hukum Asuransi dan Perusahaan Asuransi. Sinar Grafika, Jakarta.

Nasution, A. (2001). Hukum Perlindungan Konsumen Suatu Pengantar. Diadit Media, Jakarta.

Pradnyaswari, Ida Ayu Eka Westra, I. K. (2020). Upaya Perlindungan Hukum Bagi Konsumen Dalam Transaksi Jual-Beli Menggunakan Jasa E-Commerce. Kertha Semaya, 8(5), 758-766.

Rusmawati, D. E. (2013). Perlindungan Hukum Bagi Konsumen Dalam Transaksi E-Commerce. Fiat Justisia Jurnal Ilmu Hukum, 7(2), 193-201.

Saliman, A. R. (2015). Hukum Bisnis untuk Perusahaan Teori dan Contoh Kasus. Kencana, Jakarta.

Sari, I. P. (2019). Perlindungan Hukum Terhadap Konsumen Dalam Transaksi E-Commerce Berdasarkan Undang-undang Nomor 11 Tahun 2008 Tentang Informasi dan Transaksi Elektronik Beserta Undang-undang Nomor 8 Tahun 1999 Tentang Perlindungan Konsumen. Pamulang Law Review, 2(1), 13-22.

Ustadiyanto, R. (2002). Framework E-Commerce. Andi, Yogyakarta.

Wulandari, Y. S. (2018). Perlindungan Hukum bagi Konsumen terhadap Transaksi Jual Beli ECommerce. AJUDIKASI : Jurnal Ilmu Hukum, 2(2), 199-210. 